\title{
Datos interinos indican que la vacuna Sputnik V sería efectiva y segura para la prevención de COVID-19
}

\author{
Interim data indicates that Sputnik V vaccine would be effective and safe for the prevention of COVID-19
}

\author{
Comentado de: \\ Logunov DY, et al. Lancet. Feb 02, 2021. DOI:https://doi.org/10 \\ .1016/S0140-6736(21)00234-8 1
}

\section{Objetivo}

Evaluar los datos interinos sobre la eficacia y la seguridad de la vacuna de adenovirus recombinante heterólogo Gam-COVID-Vac (Sputnik V) contra el SARS-CoV-2.

\section{Diseño, lugar y participantes}

Ensayo clínico controlado con placebo y aleatorizado de fase 3 , doble ciego, realizado en 25 hospitales y policlínicos en Moscú, Rusia. Se incluyeron participantes de al menos 18 años de edad, con pruebas de reacción en cadena de la polimersa (PCR, por sus iniciales en inglés) e lgG e IgM de SARS-CoV-2 negativas, sin enfermedades infecciosas en los 14 días anteriores a su inscripción en el estudio y que no hayan recibido otras vacunas en los 30 días previos.

\section{Intervención}

Los participantes fueron asignados al azar en razón de 3:1 para recibir la vacuna o el placebo, con estratificación por edad. Los investigadores, los participantes y todo el personal del estudio fueron enmascarados a la asignación de grupo. La vacuna se administró por vía intramuscular $(0,5 \mathrm{ml} /$ dosis) en un régimen de estimulación inicial, con un intervalo de 21 días entre la primera dosis ( $r A d 26$ ) y la segunda dosis ( $\mathrm{Ad} 5$ ). Ambos vectores son portadores del gen de la glicoproteína S del SARS-CoV-2 (conocida como espiga o spike).

\section{Medición de resultados principales}

El desenlace primario fue la proporción de participantes con COVID-19 confirmado por PCR desde el día 21 después de recibir la primera dosis, incluyendo a quienes habían recibido las dos dosis y excluyendo a los participantes con violaciones del protocolo. Los eventos adversos serios se evaluaron en todos los participantes que habían recibido al menos una dosis, y los efectos adversos raros se evaluaron en todos los participantes que habían recibido dos dosis y sus datos estaban verificados al momento de cerrar la base para el análisis interino.

\section{Resultados}

Entre el 7 de septiembre y el 24 de noviembre de 2020, 21.977 adultos fueron aleatorizados a recibir la vacuna (16.501) o el placebo (5.476), de los cuales 19.866 se incluyeron en el análisis del resultado primario. Desde 21 días después de la primera dosis de vacuna (el día de la dosis 2), se confirmó que $16(0,1 \%)$ de 14,964 participantes en el grupo de vacuna y 62 (13\%) de 4.902 en el grupo de placebo tenían COVID-19. La eficacia de la vacuna fue de $91,6 \%$ (intervalo de confianza [IC] del $95 \% 85,6$ a 95,2). El $94 \%$ de los eventos adversos notificados fueron de grado leve. Se produjeron $0,3 \%$ eventos adversos graves en el grupo de la vacuna y $0,4 \%$ en el grupo de placebo. Se informaron cuatro muertes (tres en el grupo vacuna y una en el grupo placebo). Ninguno de los eventos adversos graves ni las muertes se consideraron asociados con la vacunación, con la confirmación del comité de seguimiento de datos independiente.

\section{Conclusión}

En este análisis intermedio del ensayo de fase 3, la vacuna Gam-COVID-Vac (Sputnik V) mostró una eficacia de 91,6\% contra COVID-19 y fue bien tolerada en una gran cohorte.

Fuente de financiamiento/Conflicto de interés de los autores: Este estudio es financiado por el Departamento de Salud de la ciudad de Moscú, el Fondo Ruso de Inversión Directa, Sberbank y RUSAL. La mayoría de los autores informan patentes de un vector de expresión inmunobiológica agente farmacéutico y su método de uso para prevenir COVID-19.

\section{Comentario}

La vacuna Sputnik V estuvo en el ojo de la controversia en Argentina dado que la Administración Nacional de Medicamentos, Alimentos y Tecnología Médica (ANMAT) recomendó su aprobación de emergencia sin encontrarse de manera pública los datos completos del análisis interino del ensayo clínico de fase 3 que se resumen en este artículo, en medio de disputas políticas y acusaciones sobre la adecuación de la respuesta del gobierno argentino en la gestión de la pandemia ${ }^{2}$. Si bien esta controversia se replicó en otros países y con relación a otras vacunas, en la Argentina las críticas se centraron en la Sputnik V dado que era la única vacuna potencialmente disponible en el corto plazo, mediante el establecimiento de un acuerdo de compra anticipada. Desde el inicio de la campaña de vacunación el 29 de diciembre de 2020 hasta fines de enero de 2021 se administraron 265.724 dosis en todo el país, con 12.686 eventos adversos registrados, de los cuales $97,34 \%$ fueron relacionados con la vacuna y de grado leve (fiebre, cefalea y mialgias) ${ }^{3}$.

Los datos disponibles sobre el ensayo clínico resumido indican, tras este análisis preliminar, que la vacuna es eficaz y segura; sin embargo, carecemos aún de datos sobre el resultado primario preestablecido. Si bien el protocolo del estudio no está disponible (lo cual constituye otra debilidad en el reporte de este ensayo), sus características fueron registradas prospectivamente en el registro ClinicalTrials.gov, por lo que ha trascendido que se evaluará el desenlace primario luego de los seis meses de completar el esquema de vacunación ${ }^{4}$. Todas las vacunas contra el SARS-CoV-2 cuentan con información proveniente de análisis preliminares por la emergencia contextual de la pandemia; sin embargo, la estrategia de diseminar los resultados en relación a este producto mediante comunicados de prensa -sin el reporte científico en forma- fue duramente criticado, no sólo en el ámbito de las vacunas sino también en el de otras tecnologías biomédicas ${ }^{5}$. De hecho, el análisis interino no estaba preespecificado para este estudio sino que fue establecido a posteriori; esto puede introducir sesgos y fragilidad en los resultados, especialmente en el contexto de eventos escasos en los grupos de comparación ${ }^{6}$. Sin embargo, 
la vacuna mostró eficacia en todos los subgrupos evaluados, si bien el intervalo de confianza en mayores de 60 años -los más vulnerables al virus- oscila entre $67,1 \%$ y $98,3 \%$. También se destaca que no hubo casos de COVID-19 moderados o severos en el grupo vacunado con Sputnik V, y que la mayoría de los casos leves detectados en el grupo que recibió la vacuna ocurrieron antes de recibir la segunda dosis, lo que permite especular que una dosis podría ser suficiente para lograr una efectividad aceptable. Cabe destacar que en el ensayo clínico se usó la forma líquida de la vacuna, que requiere almacenamiento a $-18^{\circ} \mathrm{C}$, si bien existe una forma disecada que puede transportarse entre 2 a $8^{\circ} \mathrm{C}$, lo que facilitaría su distribución, y que actualmente está en estudio.

Si bien los resultados mencionados son alentadores, es importante señalar al menos dos preguntas que el ensayo no responde, y para las que esperamos tener más datos en el futuro cercano:

1. ¿Cuáles son los efectos de la vacuna Sputnik $V$ en la transmisión del virus? De esto depende, principalmente, el efecto de "inmunidad de rebaño" 7 y

2. ¿Cuál es la duración de la inmunidad provista por la vacuna? Teniendo en cuenta lo que sabemos de la escasa duración de la inmunidad sostenida a la familia de virus similares al SARS-CoV- ${ }^{8}$.

Sin embargo, estas preguntas no deberían retrasar la implementación efectiva de la vacunación masiva a la población con algunas de las vacunas que están siendo probadas como seguras y efectivas a corto plazo, a la cual Sputnik V se suma, con este estudio, a la lista.

\section{Conclusiones del comentador}

La vacuna Sputnik $V$ ha demostrado ser efectiva y segura en este análisis preliminar. Si bien es necesario tener datos más robustos para confirmar los hallazgos, y quedan algunos interrogantes pendientes sobre el efecto de la vacuna en la transmisión y la duración de la inmunidad, la vacunación con este producto puede contribuir significativamente a la reducción de la morbimortalidad por COVID-19.

Juan Victor Ariel Franco [ Departamento de Investigación y Centro Cochrane, Instituto Universitario Hospital Italiano de Buenos Aires; Servicio de Medicina Familiar y Comunitaria, Hospital Italiano de Buenos Aires; Departamento de Salud, Universidad Nacional de La Matanza. juan.franco@ hospitalitaliano.org.ar ]

Franco JVA Datos interinos indican que la vacuna Sputnik V sería efectiva y segura para la prevención de COVID-19. Evid Actual Pract Ambul. 2021;24(1):e002120. Comentado de: Logunov DY, et al. Safety and efficacy of an rAd26 and rAd5 vector-based heterologous prime-boost COVID-19 vaccine: an interim analysis of a randomised controlled phase 3 trial in Russia. Lancet. Feb 02, 2021. DOI:https://doi.org/10.1016/S0140-6736(21)002348

\section{Referencias}

1. Logunov DY, Dolzhikova IV, Shcheblyakov DV, et al. Safety and efficacy of an rAd26 and rAd5 vector-based heterologous prime-boost COVID-19 vaccine: an interim analysis of a randomised controlled phase 3 trial in Russia. Lancet. 2021;Available from: 10.1016/S0140-6736(21)00234-8.

2. Limeres M. Argentina. ANMAT. Informe técnico de perfil regulatorio sobre autorización de uso de vacuna Sputnik $V$ en el marco de la ley 27.573 ; 2020. Available from: https://www.argentina.gob.ar/noticias/informe-de-la-anmat-sobre-la-vacuna-sputnik-v.

3. Argentina. Ministerio de Salud. Campaña Nacional de Vacunación contra la COVID-19. $5^{\circ}$ Informe de vigilancia de seguridad en vacunas 29 de enero de 2021.; 2021. Available from: https://bancos.salud.gob.ar/recurso/quinto-informe-de-seguridad-en-vacunas.

4. Gamaleya Research Institute of Epidemiology and Microbiology, Health Ministry of the Russian Federation. Clinical Trial of Efficacy, Safety, and Immunogenicity of Gam-COVID-Vac Vaccine Against COVID-19; 2020. Available from: https://clinicaltrials.gov/ct2/show/NCT04530396.

5. McMahon JH, Lydeamore MJ, Stewardson AJ. Bringing evidence from press release to the clinic in the era of COVID-19. J Antimicrob Chemother. 2020;p. dkaa506. Available from: 10.1093/jac/dkaa506;https://dx.doi.org/10.1093/jac/dkaa506.

6. Garegnani LI, Arancibia M, Madrid E, et al. Clinical trials with sequential analysis that were early-stopped: How to interpret them? . Medwave. 2020;20(5):e7930. Available from: 10.5867/medwave.2020.05.7930.

7. Randolph HE, Barreiro LB. Herd Immunity: Understanding COVID-19. Immunity. 2020;52(5):737-741. Available from: 10.1016/j.immuni.2020.04. 012;https://dx.doi.org/10.1016/j.immuni.2020.04.012.

8. Poland GA, Ovsyannikova IG, Kennedy RB. SARS-CoV-2 immunity: review and applications to phase 3 vaccine candidates. Lancet. 2020;396(10262):1595-1606. Available from: 10.1016/s0140-6736(20)32137-1; https://dx.doi.org/10.1016/s0140-6736(20)32137-1. 